\title{
A Compact Lowpass Filter for Satellite Communication Systems Based on Transfer
}

\section{Function Analysis}

Ali Lalbakhsh, Mohammad (Behdad) Jamshidi, Hesam Siahkamari, Amirhossein Ghaderi, Alireza Golestanifar, Richard Linhart, Jakub Talla, Roy B. V. B. Simorangkir, and Kaushik Mandal

Dr. Ali Lalbakhsh ( $\mathrm{PhD}$ in Electronics Engineering) is with the School of Engineering, Macquarie University, NSW, Australia, Email: ali.lalbakhsh@mq.edu.au.com (Corresponding author)

Mr. Mohammad (Behdad) Jamshidi is a PhD student in the Department of Electromechanical Engineering and Power Electronics (KEV), Faculty of Electrical Engineering of the University of West Bohemia, Email: jamshidi@kev.zcu.cz

Mr. Hesam Siahkamari is a PhD student in in the Department of Applied Electronics and Telecommunications (KAE), Faculty of Electrical Engineering of the University of West Bohemia, Email: hesam@kae.zcu.cz

Mr. Amirhossein Ghaderi (Master in Electronics Engineering) is a senior researcher at Young Researchers and Elite Club, Kermanshah Branch, Islamic Azad University, Kermanshah, Iran, Email: amir92h@yahoo.com

Alireza Golestanifar (Master in Electronics Engineering) is a senior researcher at Young Researchers and Elite Club, Kermanshah Branch, Islamic Azad University, Hamedan, Iran, Master of Electronics Engineering, Email: golestany950@yahoo.com

Dr. Richard Linhart (PhD in Electronics Engineering) is an Assistant Professor in the Department of Applied Electronics and Telecommunications (KAE), Faculty of Electrical Engineering of the University of West Bohemia, Email: rlinhart@kae.zcu.cz

Dr. Jakub Talla (PhD in Electrical Engineering) is an Assistant Professor in the Department of Electromechanical Engineering and Power Electronics (KEV), Faculty of Electrical Engineering of the University of West Bohemia, Email: talic@rice.zcu.cz

Dr. Roy B. V. B. Simorangkir ( $\mathrm{PhD}$ in Electronics Engineering) is a research associate at University of Rennes 1, CNRS, Institut d'Electronique et de Tel' ecommunications of Rennes (IETR)-UMR 6164, F35000 Rennes, France. Email: roy.simorangkir@ieee.org

Kaushik Mandal is an Assistant Professor in the Institute of Radio Physics and Electronics, University of Calcutta, West Bengal, India, kaushikrpe@gmail.com 
Abstract: This paper presents a very efficient design procedure for a highperformance microstrip lowpass filter (LPF). Unlike many other sophisticated design methodologies of microstrip LPFs, which contain complicated configurations or even over-engineering in some cases, this paper presents a straightforward design procedure to achieve some of the best performance of this class of microstrip filters. The proposed filter is composed of three different polygonal-shaped resonators, two of which are responsible for stopband improvement, and the third resonator is designed to enhance the selectivity of the filter. A holistic performance assessment of the proposed filter is presented using a Figure of Merit (FOM) and compared with some of the best filters from the same class, highlighting the superiority of the proposed design. A prototype of the proposed filter was fabricated and tested, showing a 3-dB cut-off frequency $\left(f_{c}\right)$ at 1.27 GHz, having an ultrawide stopband with a suppression level of $25 \mathrm{~dB}$, extending from 1.6 to $25 \mathrm{GHz}$. The return loss and the insertion loss of the passband are better than $20 \mathrm{~dB}$ and $0.25 \mathrm{~dB}$, respectively. The fabricated filter has a high FOM of 76331, and its lateral size is $22.07 \mathrm{~mm} \times 7.57 \mathrm{~mm}$.

Introduction: Microstrip technology has been extensively used for implementation of microwave passive and active components, due to its low-cost fabrication process and its versatile characteristics [1-6]. Microstrip filters (LPFs) play a critical role in modern communication systems for suppressing unwanted harmonics, as they are easily integrated with other microwave components. Therefore, passive LPFs with a small size, wide stopband, and low cost are highly in demand [7]. Such high-performance filters will play a significant role in the upcoming new generation of the low-cost satellite communications technology, where the size and the cost of the Earth receiver stations are critical. This is even more important for the 
communication-one-the-move, where in addition to all strict satellite communication requirements, there is a strong motivation to employ passive, affordable microwave and electromagnetic components in the portable satellite receivers [8-11]. Thus, various techniques have been studied to achieve LPFs with the mentioned features [12-27]. A modified version of T-shaped resonators in conjunction with multiple open-stubs was proposed in [12] to realize a compact LPF with a large stopband. In a different approach, a new E-type feeding structure was proposed to feed a cross-shaped patch reonator to minimize the passband insertion loss [13]. Coupled rhombic stubs were proposed in [14] to improve both stopband and out-of-band rejection. While the design procedures in [12], [14] have been successful in some factors of merit, their roll-offs were reported to be around $50 \mathrm{~dB} / \mathrm{GHz}$. To achieve high selectivity, tapered sectorial resonators and large radial stubs were proposed in [15] and [16], respectively. Despite the very sharp responses realized in these two works, both procedures resulted in a relatively large circuit size. Other methods, such as stepped-impedance [13-17], pendulumshaped resonator [18] and spiral lines [19], have been proposed for wide-stopband applications. Similar out-of-band performance along with a strong harmonic attenuation can be achieved using defected ground structures [20,21]; however, the implementation complexity is considered as the associated challenge with this technique.

In [22], a high-impedance transmission-line is loaded by multiple compact microstrip resonant cells to provide both high selectivity and wide stopband, while the circuit size is not equally weighted, resulting in a relatively large filter. In [23-27], numerical-based approaches were used to predict the transfer function of a lowpass filter and to extract its resonant frequencies. With the development of nature-based optimization algorithms, such as ant colony optimization [28-29], neural networks [30-34] and particle swarm optimization [35-36], a new avenue of research in the microwave and electromagnetic community has been established, 
where several customized optimization algorithms in conjunction with electromagnetic (EM) simulators have been used to design and optimize a wide range of microwave and EM components, such as filters, power dividers, frequency selective surfaces [37-44]. Apart from the above-mentioned applications, microstrip LPFs are integrated with other microwave components, such as power-dividers with harmonic suppression capability [45-46]. In [47], a symmetric LPF composed of several square resonators was used to attenuate the reflected signals throughout the passband up to $15 \mathrm{~dB}$, whereas the transition band is relatively large. Defected ground structure (DGS) has been reported as another technique for harmonic suppression in LPFs, considerably extending the stopband range [48],[49]. However, the attenuation level in the stopband of these filters are less than $18 \mathrm{~dB}$, and the return loss in the passband is around only $10 \mathrm{~dB}$. Also, radial-shaped and semi-circle patch resonators were applied in [50], even though it suffers from a narrow stopband. Reviewing related literature reveals that most approaches mainly focus on improving one or some of the critical properties of the LPFs, while other aspects, particularly design complications, are sacrificed or neglected. Hence, we propose a very simple, yet systematic design methodology, to reasonably satisfy all factors of merit and achieve a significantly greater FOM than many recently published LPFs. The presented filter is compact with total area of only $0.0048 \lambda_{\mathrm{g}}{ }^{2}$, where $\lambda_{\mathrm{g}}$ is the guided wavelength at the cut-off frequency. The measured transition band extends from $1.27 \mathrm{GHz}$ to 1.67 $\mathrm{GHz}$ with attenuation levels of -3 and $-40 \mathrm{~dB}$, respectively. The spurious signals are significantly suppressed from $1.6 \mathrm{GHz}$ up to $25 \mathrm{GHz}$, which is about $19 \mathrm{f}_{\mathrm{c}}$. The proposed LPF operating at $1.27 \mathrm{GHz}$ with wide stopband and miniaturized dimensions is a good candidate for the satellite communication technology. All simulations are carried out by ADS Momentum on an RT-5880 substrate with a thickness of $0.381 \mathrm{~mm}$. 
Filter Design: The proposed procedure is composed of three steps, delivering three different cells with different functionalities essential for the filter design. First, a wideband suppressing cell with a high attenuation level is designed to ensure the wide-stopband capability of the filter. To do this, a pair of T-shaped resonators is placed on a high-impedance transmission line, as shown in Fig. 1(a). In this figure, Vi and Vo represent the input and output signals. The proposed structure is modeled by a LC equivalent circuit to verify the suppression capability. In addition to the LC model analysis, even and odd mode analysis can be used to justify the filtering behavior of the microstrip filters as explained in [51], [52]. In LC model proposed, L1, L2 and C1 are inductances and capacitance of the transmission line, respectively. L3 and C2 denote the inductance and capacitance of the high impedance lines of the T-shaped resonators, respectively. The inductance and capacitance of the low impedance stub are introduced by L4 and C3, respectively. Lumped-element values are calculated and optimized using the methods described in $[7,16]$. The $\mathrm{LC}$ values of the resonator are as follows: $\mathrm{C} 1=0.24$ $\mathrm{pF}, \mathrm{C} 2=0.28 \mathrm{pF}, \mathrm{C} 3=0.24 \mathrm{pF}, \mathrm{L} 1=1.62 \mathrm{nH}, \mathrm{L} 2=4.2 \mathrm{nH}, \mathrm{L} 3=0.25 \mathrm{nH}$ and $\mathrm{L} 4=0.4 \mathrm{nH}$. This cell is designed to create a deep transmission zero at $12 \mathrm{GHz}$ with an ultrawide stopband.

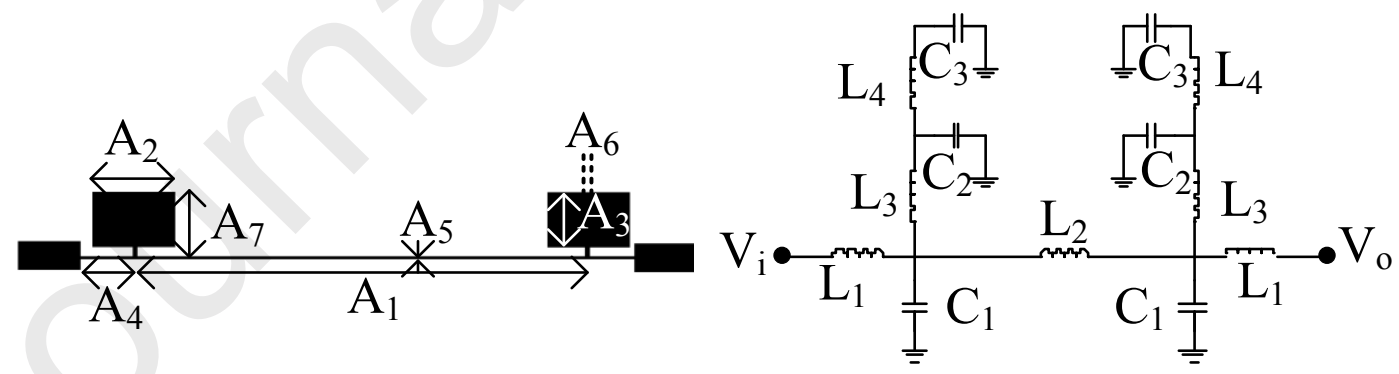

(a) 


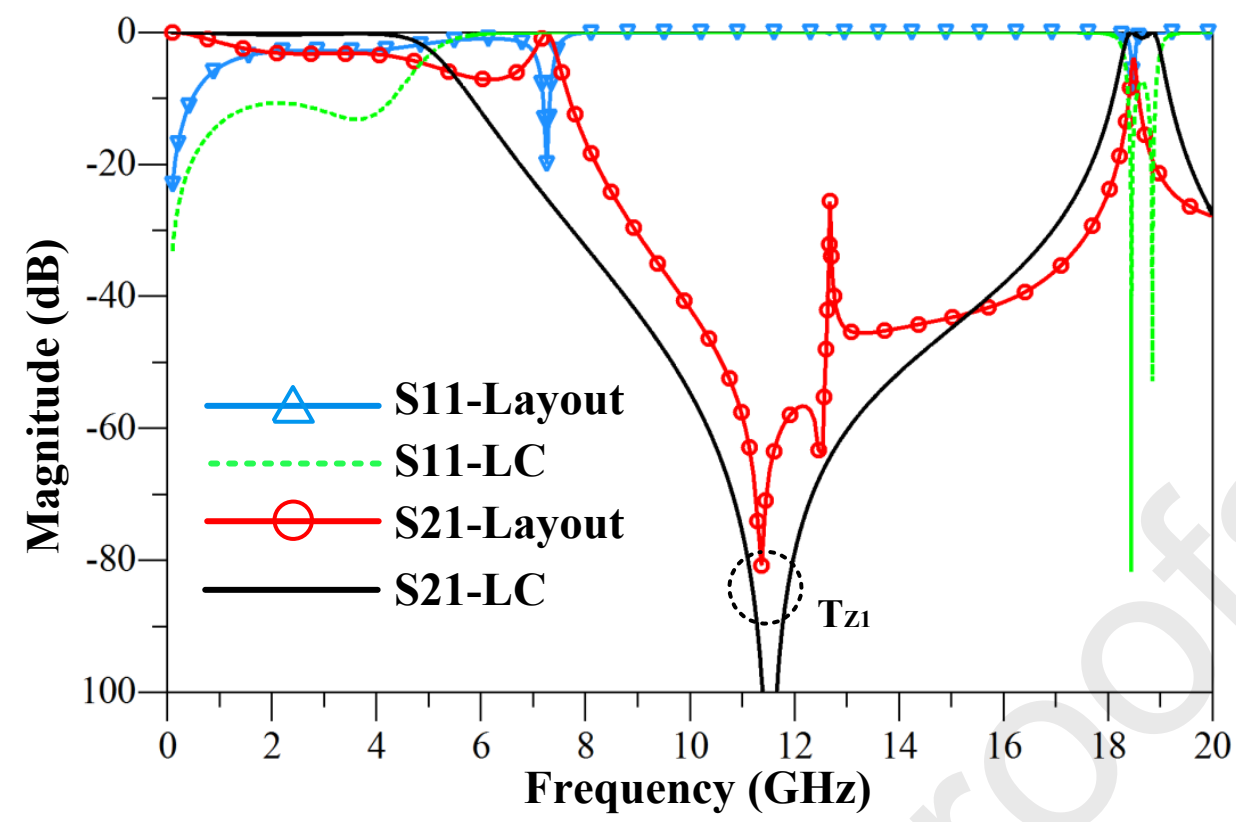

(b)

Fig. 1 The proposed wideband suppressing cell. (a)Layout and LC equivalent circuit. (b) EM and LC simulation results.

Fig. 1 (b) shows the EM and LC responses. To analyze and verify the operation of the LC model, transfer function of the T-shaped resonators is computed as (1). The formula of the first transmission zero $\left(\mathrm{Tz}_{1}\right)$ is attained by equating the transfer function to zero as (2). Notice, $r$ is the matching impedance of input and output ports $(\mathrm{r}=50 \Omega)$. As seen, the equation of $\mathrm{Tz}_{1}$ is relared to LC parameters, so that its location can be easily relocated by varying LC values.

$\frac{v_{o}}{v_{i}}=\frac{2 r d}{d L_{1} s+L_{1} s\left(c L_{1} s+b+d\right)+L_{2} s\left(c L_{1} s+d\right)+r^{2} a d+a d r L_{1} s+2 r+r c L_{1} s+r c L_{2} s+2 r d}$,

where

$$
a=\left(\frac{2 c d+c^{2} L_{2} s}{d^{2}}\right)
$$




$$
\begin{gathered}
b=\left(L_{1} s+L_{2} s\left(\frac{c L_{1} s}{d}+1\right)\right) c \\
c=C_{1} C_{2} C_{3} L_{3} L_{4} s^{5}+\left(C_{1} C_{2} L_{3}+C_{1} C_{3} L_{3}+C_{1} C_{3} L_{4}+C_{2} C_{3} L_{4}\right) s^{3}+\left(C_{1}+C_{2}+C_{3}\right) s, \\
d=C_{2} C_{3} L_{3} L_{4} s^{4}+\left(C_{2} L_{3}+C_{3} L_{3}+C_{3} L_{4}\right) s^{2}+1 \\
T_{Z 1}=\left|\frac{\sqrt{-\frac{C_{2} L_{3}+C_{3} L_{3}+C_{3} L_{4}-\sqrt{\left(C_{2} L_{3}+C_{3} L_{3}+C_{3} L_{4}\right)^{2}-4 C_{2} C_{3} L_{3} L_{4}}}{2 C_{2} C_{3} L_{3} L_{4}}}}{2 \pi}\right|
\end{gathered}
$$

Location of $\mathrm{Tz}_{1}$ is related to the $\mathrm{LC}$ values, particularly the values of $\mathrm{L} 3, \mathrm{~L} 4$ and $\mathrm{C} 3$ which represent the T-shaped resonators equivalent model. Fig 2 shows the effects of varying L4, L3 and $\mathrm{C} 3$. The sweep range of $\mathrm{L} 3$ and $\mathrm{L} 4$ is 0 to $1 \mathrm{nH}$ and the sweep range of $\mathrm{C} 3$ is between 0 to $1 \mathrm{pF}$. As can be seen, by decresing the vlaues of $\mathrm{L} 4$ and $\mathrm{L} 3, \mathrm{Tz}_{1}$ shifts to higher frequencies, extending the stopband, while the cut off frequency is less affected by variation of L4 cpompared to L3. The next parameter which is effective to alter stopband range is C3. According to Fig 2, it is seen that decreasing the value of $\mathrm{C} 3$ increaes the stopband and cut off frequency. It should be noticed that for swept values of L4, L3 and C3 only the one parameter is swepted and the others are fixed 


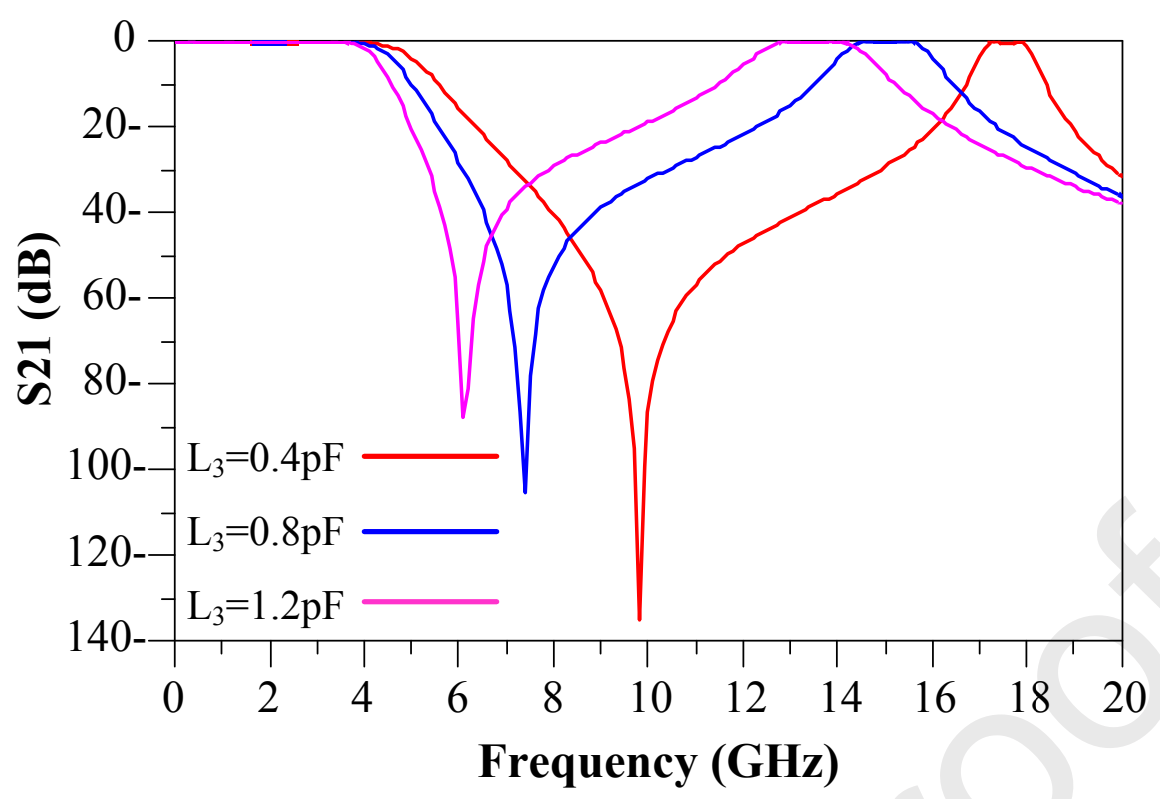

(a)

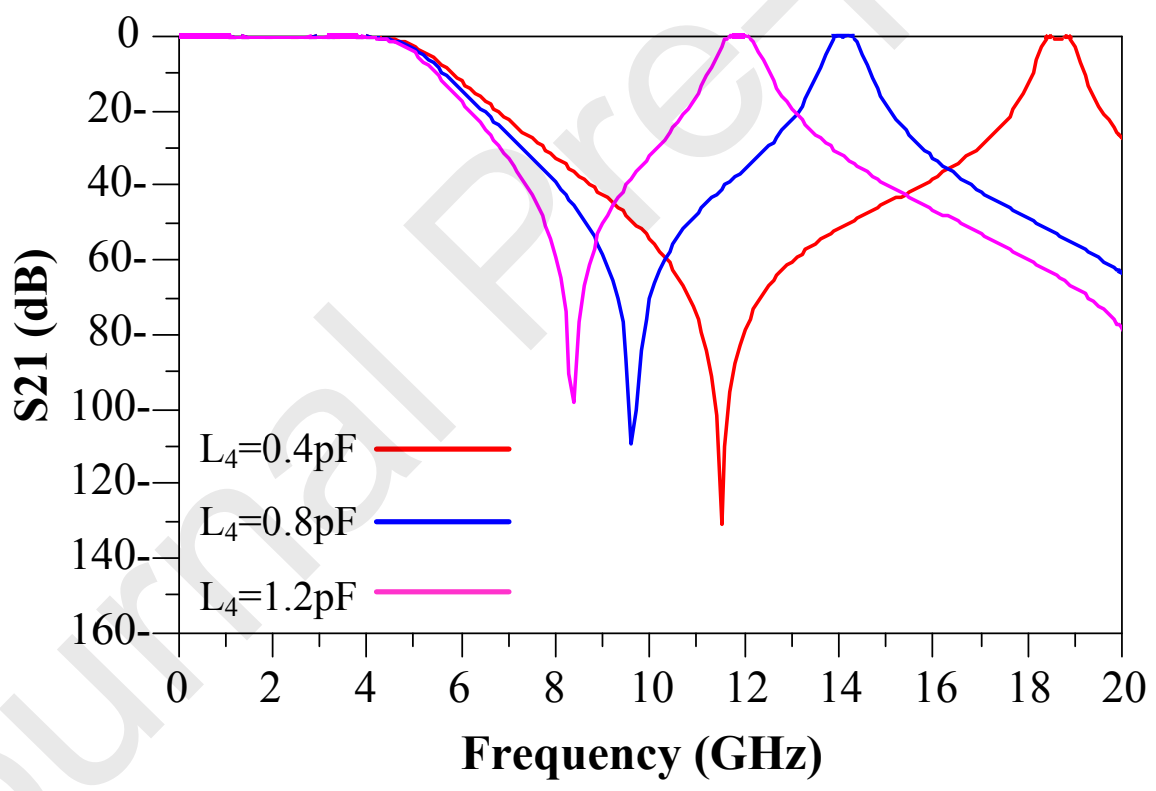

(b) 


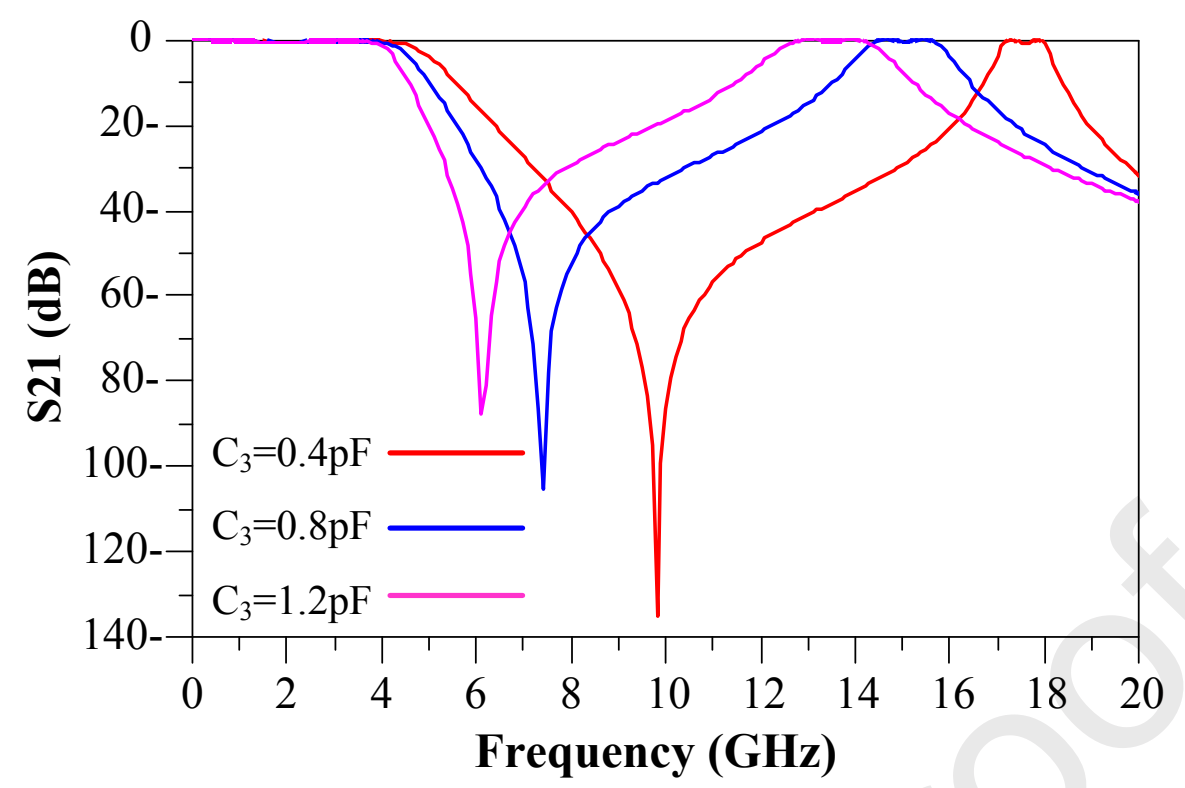

(c)

Fig. 2. Variation of $T z_{1}$ and its effects on the frequency reponse of the filter versus the different values of $L 4, L 3$ and $C 3$.

Octagonal Resonator: In the second step, another suppression cell is designed with the advantage of providing a smaller transition band. This characteristic contributes to a higher selectivity in the filtering mechanism of the proposed LPF. To do so, an octagonal resonator along with its LC model with a transmission zero tuned at $5 \mathrm{GHz}$ is designed and shown in Fig. 3.

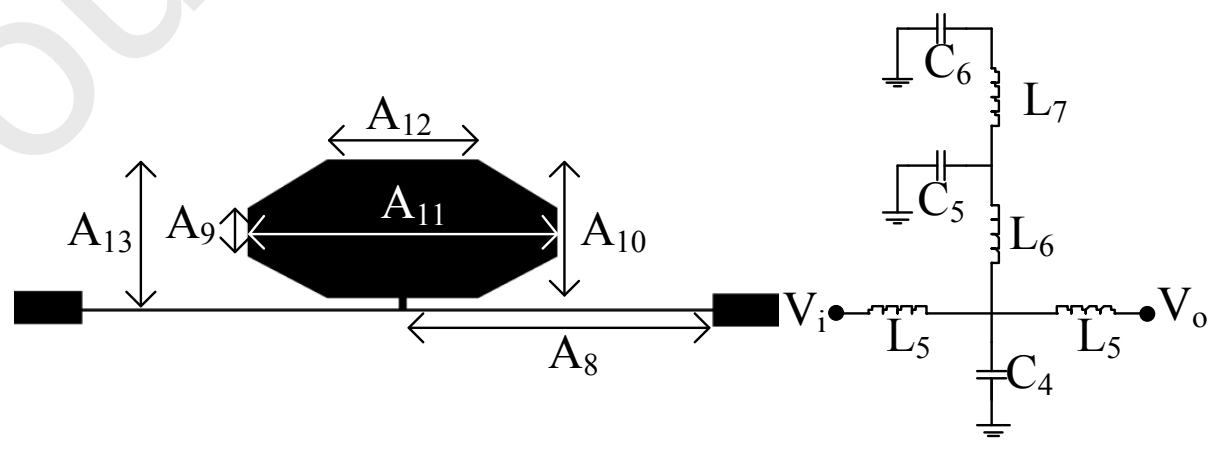




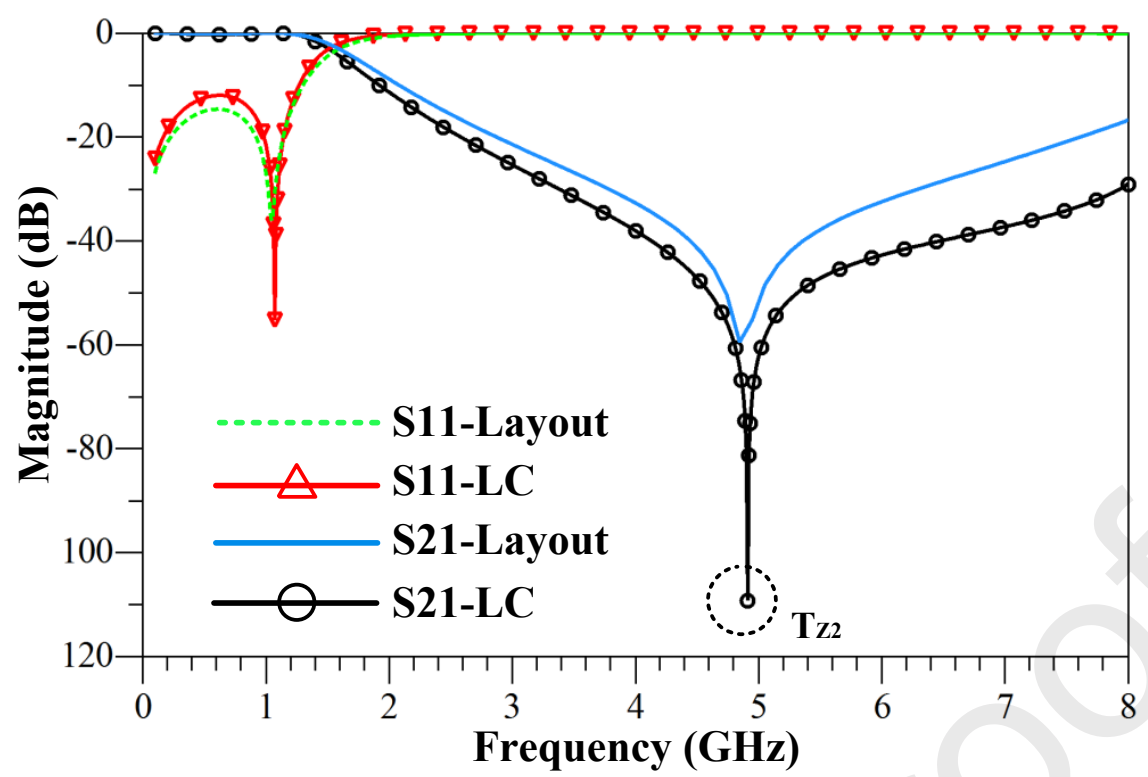

(b)

Fig. 3 Octagonal suppression cell. (a) Layout and equivalent circuit. (b) EM and LC simulation results.

In the LC model, the inductor and the capacitor associated with the transmission line are represented by L5 and C4, respectively. L6 and C5 are inductance and capacitance of the highimpedance line of octagonal resonator, respectively. In addition, the capacitor and the inductor of the octagonal-shaped stub are C6 and L7, respectively. The values of the lumped elements of the octagonal resonator are as follows: $\mathrm{C}_{4}=0.27 \mathrm{pF}, \mathrm{C}_{5}=1.08 \mathrm{pF}, \mathrm{C}_{6}=1.49 \mathrm{pF}, \mathrm{L}_{5}=8.51 \mathrm{nH}$, $\mathrm{L}_{6}=0.17 \mathrm{nH}, \mathrm{L}_{7}=0.50 \mathrm{nH}$. The suppression performance of the proposed cell is verified by its EM and LC responses in Fig. 3. The transfer function of the octagonal resonator and the equation of $\mathrm{Tz}_{2}$ are calculated and represented in (3) and (4), respectively.

$$
\frac{v_{o}}{v_{i}}=\frac{2 r}{L_{5} S\left(L_{5} C_{4} S^{2}+b+1\right)+r\left(L_{5} C_{4} S^{2}+a L_{5} S+b+2\right)+r^{2} a+L_{5} S},
$$

where 


$$
\begin{gathered}
a=\left(\frac{C_{5} C_{6} L_{7} S^{3}+\left(C_{5}+C_{6}\right) S}{C_{5} C_{6} L_{7} L_{6} S^{4}+\left(C_{5} L_{6}+C_{6} L_{6}+C_{6} L_{7}\right) S^{2}+1}+C_{4} S\right), \\
b=\left(\frac{L_{5} S\left(C_{5} C_{6} L_{7} S^{3}+\left(C_{5}+C_{6}\right) S\right)}{C_{5} C_{6} L_{7} S^{4}+\left(C_{5} L_{6}+C_{6} L_{6}+C_{6} L_{7}\right) S^{2}+1}\right) . \\
T_{Z 2}=\left|\frac{\sqrt{-\frac{C_{5} L_{6}+C_{6} L_{6}+C_{6} L_{7}-\sqrt{\left(C_{5} L_{6}+C_{6} L_{6}+C_{6} L_{7}\right)^{2}-4 C_{5} C_{6} L_{6} L_{7}}}{2 C_{5} C_{6} L_{6} L_{7}}}}{2 \pi}\right|
\end{gathered} .
$$

In the third step, the desired cut-off frequency of the filter is realized using a very-sharpresponse cell. So, two pentagonal resonators are proposed to introduce a significantly deep transmission zero, placed very close to the desired cut-off frequency, as shown in Fig. 4.

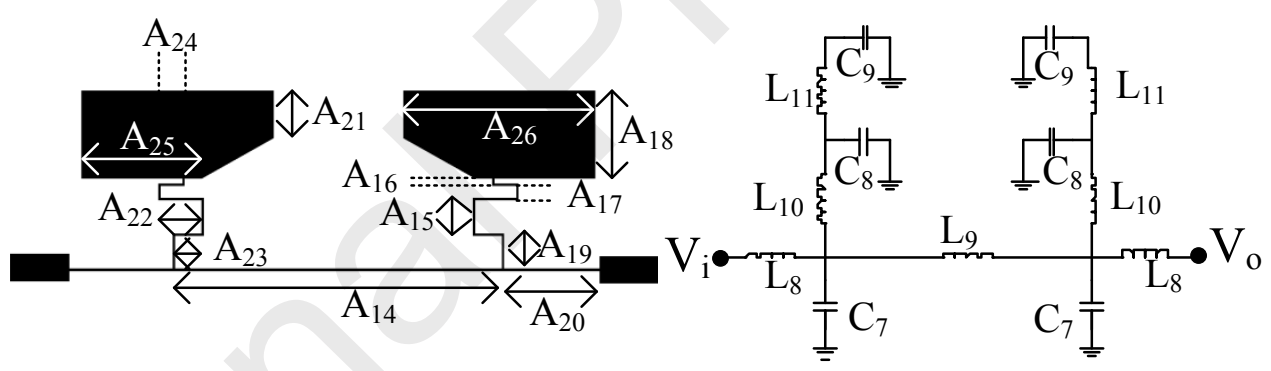

(a) 


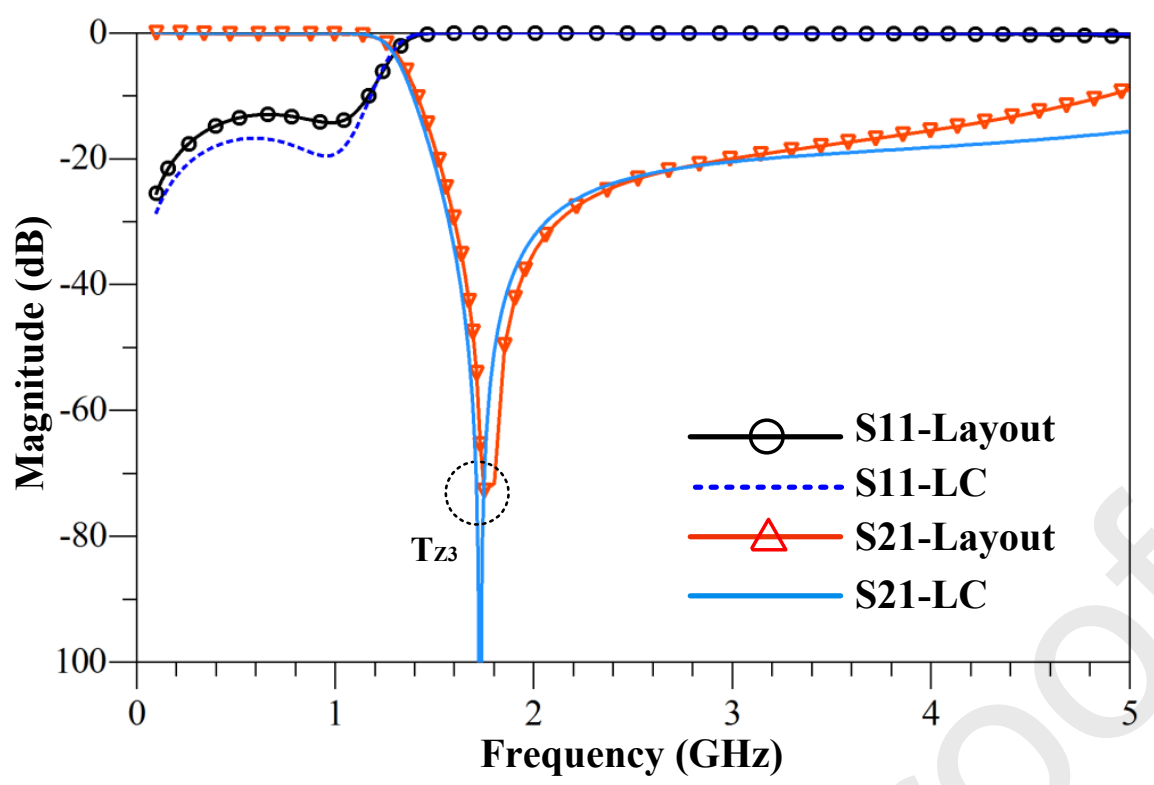

(b)

Fig. 4Pentagonal resonators. (a) The layout and the equivalent circuit. (b) The EM and LC simulation results.

As can be seen from the LC and EM responses, there is a strong transmission zero at $2 \mathrm{GHz}$, due to the identical pentagonal resonators. In the LC model of pentagonal resonators, L8, L9 and $\mathrm{C} 7$ show inductances and capacitance of the transmission line, respectively. L10 and C8 are inductor and capacitor of the high-impedance lines of the pentagonal resonators, respectively. The inductor and capacitor of the pentagonal-shaped stubs are depicted by L11 and $\mathrm{C} 9$, respectively. The values of the lumped elements are as follows: $\mathrm{C}_{7}=0.24 \mathrm{pF}, \mathrm{C}_{8}=0.77$ $\mathrm{pF}, \mathrm{C}_{9}=1.16 \mathrm{pF}, \mathrm{L}_{8}=3.32 \mathrm{nH}, \mathrm{L}_{9}=10.26 \mathrm{nH}, \mathrm{L}_{10}=4.36 \mathrm{nH}, \mathrm{L}_{11}=0.08 \mathrm{nH}$. The formula of $\mathrm{Tz}_{3}$ is obtained as (6) using transfer function of pentagonal resonators in (5). The physical dimensions of the proposed LPF are classified in Table 1. 
$\frac{v_{o}}{v_{i}}=\frac{2 r d}{d L_{8} s+L_{8} s\left(c L_{8} s+b+d\right)+L_{9} s\left(c L_{8} s+d\right)+r^{2} a d+a d r L_{8} s+2 r+r c L_{8} s+r c L_{9} s+2 r d}$,

where

$$
\begin{gathered}
a=\left(\frac{2 c d+c^{2} L_{9} s}{d^{2}}\right), \\
b=\left(L_{8} s+L_{9} s\left(\frac{c L_{8} s}{d}+1\right)\right) c \\
c=C_{7} C_{8} C_{9} L_{10} L_{11} s^{5}+\left(C_{7} C_{8} L_{10}+C_{7} C_{9} L_{10}+C_{7} C_{9} L_{11}+C_{8} C_{9} L_{11}\right) s^{3}+\left(C_{7}+C_{8}+C_{9}\right) s, \\
d=C_{8} C_{9} L_{10} L_{11} s^{4}+\left(C_{8} L_{10}+C_{9} L_{10}+C_{9} L_{11}\right) s^{2}+1 . \\
T_{Z 3}=\left|\frac{\sqrt{-\frac{C_{8} L_{10}+C_{9} L_{10}+C_{9} L_{11}-\sqrt{\left(C_{8} L_{10}+C_{9} L_{10}+C_{9} L_{11}\right)^{2}-4 C_{8} C_{9} L_{10} L_{11}}}{2 C_{8} C_{9} L_{10} L_{11}}}}{2 \pi}\right|
\end{gathered} .
$$

Table 1: The physical dimensions of the proposed LPF

\begin{tabular}{|c|c|c|c|c|c|c|c|c|c|}
\hline Parameter & $\mathrm{A}_{1}$ & $\mathrm{~A}_{2}$ & $\mathrm{~A}_{3}$ & $\mathrm{~A}_{4}$ & $\mathrm{~A}_{5}$ & $\mathrm{~A}_{6}$ & $\mathrm{~A}_{7}$ & $\mathrm{~A}_{8}$ & $\mathrm{~A}_{9}$ \\
\hline $\begin{array}{c}\text { Value } \\
(\mathrm{mm})\end{array}$ & 17.8 & 3.3 & 2.2 & 1.8 & 0.1 & 0.2 & 2.6 & 10.7 & 1.7 \\
\hline Parameter & $\mathrm{A}_{10}$ & $\mathrm{~A}_{11}$ & $\mathrm{~A}_{12}$ & $\mathrm{~A}_{13}$ & $\mathrm{~A}_{14}$ & $\mathrm{~A}_{15}$ & $\mathrm{~A}_{16}$ & $\mathrm{~A}_{17}$ & $\mathrm{~A}_{18}$ \\
\hline $\begin{array}{c}\text { Value } \\
(\mathrm{mm})\end{array}$ & 4.9 & 10.8 & 5.3 & 5.30 & 13.6 & 1.6 & 0.3 & 0.7 & 3.7 \\
\hline Parameter & $\mathrm{A}_{19}$ & $\mathrm{~A}_{20}$ & $\mathrm{~A}_{21}$ & $\mathrm{~A}_{22}$ & $\mathrm{~A}_{23}$ & $\mathrm{~A}_{24}$ & $\mathrm{~A}_{25}$ & $\mathrm{~A}_{26}$ & \\
\hline $\begin{array}{c}\text { Value } \\
(\mathrm{mm})\end{array}$ & 1.5 & 4.0 & 2.0 & 1.8 & 1.2 & 1.0 & 5.0 & 8.0 & \\
\hline
\end{tabular}

The current disributions of the final structure at the cut off frequency $(1.27 \mathrm{GHz})$ and a typical frequency in the stopband $(3.21 \mathrm{GHz})$ are ploted in Figs. 6a and 6b. As observed, the current density is stronger at $1.27 \mathrm{GHz}$ and the flow is suppressed at the stopband. 


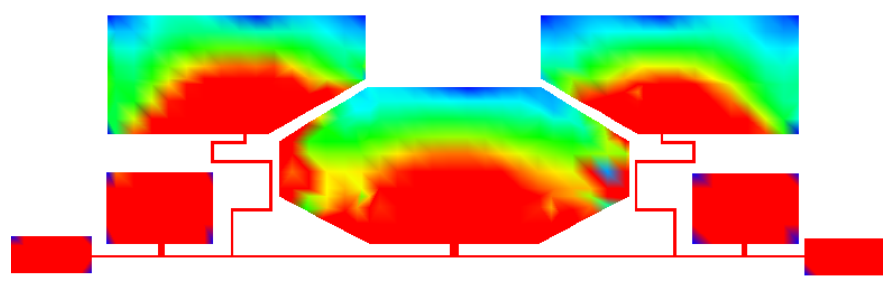

(a)

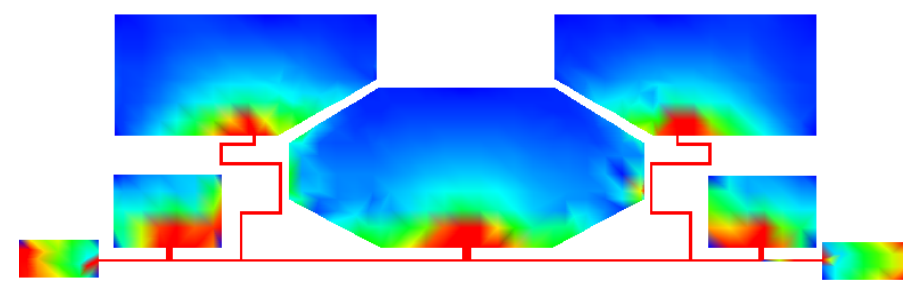

(b)

Fig. 5. Current distributions of the proposed LPF. (a) Cut-off frequency (1.27 GHz), (b) Stopband area $(3.21 \mathrm{GHz})$

Measurement Results: To verify the presented design approach, a prototype LPF was fabricated and measured, as shown in Fig. 6a. The fabricated model is implemented on an RT-5880 substrate with a thickness of $0.381 \mathrm{~mm}$. The S-parameters of the filter were measured using an Agilent vector network analyzer (E8361 C) and shown in Fig. 6b. Fig. 6c shows the variation of group delay (GD) throughout the passband is only $0.7 \mathrm{~ns}$, depicting a flat response. According to these figures, the frequency response of the proposed filter has a 3-dB cut-off frequency of $1.27 \mathrm{GHz}$ with a very small transition band. The filter exhibits excellent in-band and out-of-band characteristics, providing a super ultrawide stopband, extending from $1.6 \mathrm{GHz}$ up to $25 \mathrm{GHz}$, which is about $19 \mathrm{f}_{\mathrm{c}}$. The return loss and the insertion loss in the passband are better than $20 \mathrm{~dB}$ and $0.25 \mathrm{~dB}$, respectively, showing a flat and stable passband. The filter is compact, with a size of $0.12 \lambda \mathrm{g} \times 0.04 \lambda \mathrm{g}$ (where $\lambda \mathrm{g}$ is the guided wavelength at $1.27 \mathrm{GHz}$ ). Table 2 summarizes a comparison between some of the newly reported LPFs and the proposed one, based on the specifications explained in [16] and [23]. 


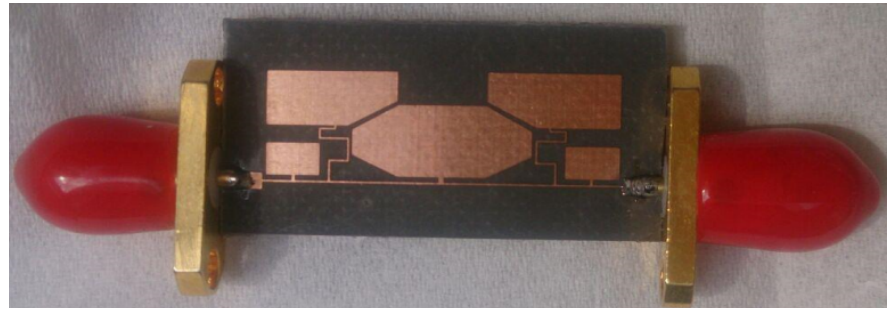

(a)

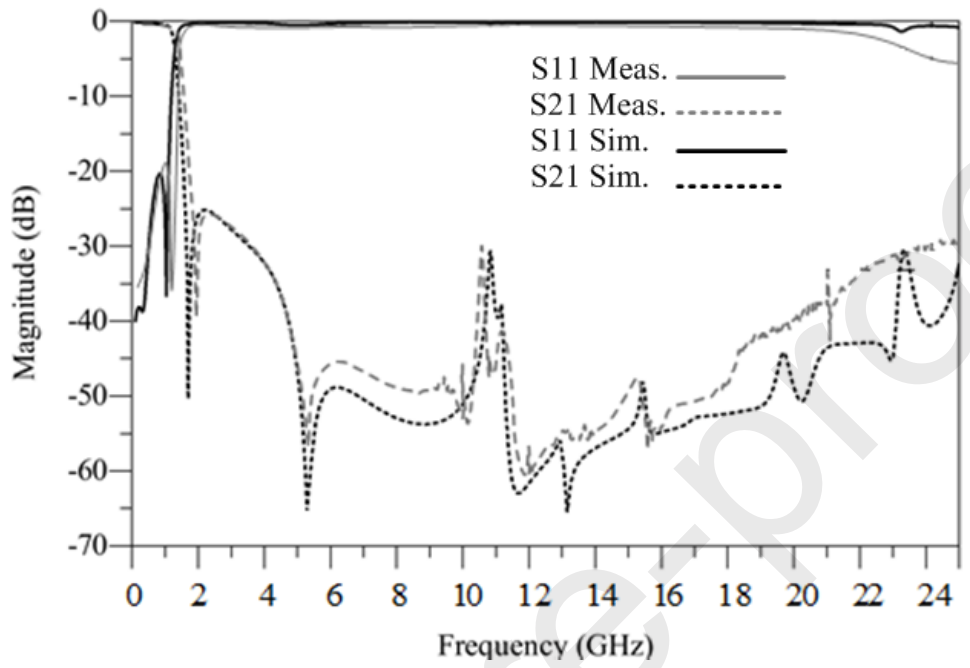

(b)

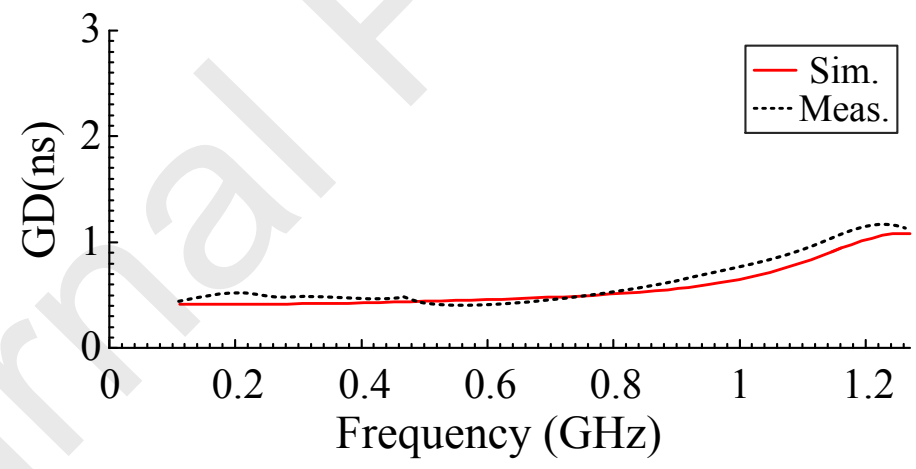

(c)

Fig. 6. The proposed LPF. (a) Fabricated prototype, (b) Simulated and measured results,

(c) Group delay 
Table 2: Performance comparison of the proposed filter with some other published.

\begin{tabular}{c|ccccccc}
\hline Ref. & $\boldsymbol{R O}(\boldsymbol{\xi})$ & $\boldsymbol{R S B}$ & $\boldsymbol{S F}$ & $\boldsymbol{N C S}$ & $\boldsymbol{A F}$ & $\boldsymbol{F O M}$ & $\boldsymbol{R} \boldsymbol{L}(\boldsymbol{d B})$ \\
\hline$[13]$ & 40.2 & 1.60 & 1.5 & $0.09 \times 0.13$ & 1 & 8,246 & 36 \\
{$[14]$} & 57.8 & 1.61 & 3.5 & $0.12 \times 0.10$ & 1 & 27,142 & 10 \\
{$[15]$} & 104 & 1.80 & 2 & $0.19 \times 0.12$ & 1 & 20,464 & 12 \\
{$[16]$} & 217 & 1.65 & 2 & $0.29 \times 0.12$ & 1 & 19,931 & 10 \\
{$[17]$} & 75 & 1.66 & 2 & $0.11 \times 0.08$ & 1 & 28,040 & 20 \\
{$[19]$} & 77 & 1.74 & 2.4 & $0.09 \times 0.13$ & 1 & 25,247 & 20 \\
{$[47]$} & 20 & 1.7 & 1 & $0.054 \times 0.070$ & 1 & 9190 & 15 \\
{$[48]$} & 100 & 1.6 & 1.8 & 0.032 & 1 & 9000 & 12 \\
{$[49]$} & 37.2 & 1.62 & 1.5 & $0.18 \times 0.21$ & 1 & 2391 & 10 \\
{$[50]$} & 14 & 1.5 & 1.5 & $0.06 \times 0.08$ & 1 & 6468 & 15 \\
\hline This work & $\mathbf{9 2 . 5}$ & $\mathbf{1 . 7 6}$ & $\mathbf{2 . 5}$ & $\mathbf{0 . 0 4} \times \mathbf{0 . 1 2}$ & $\mathbf{1}$ & $\mathbf{7 6 , 3 3 1}$ & $\mathbf{2 0}$ \\
\hline
\end{tabular}

In table 2, the roll-off rate $(\boldsymbol{\xi})$ is defined as:

$\xi=\frac{\alpha_{\max }-\alpha_{\min }}{f_{s}-f_{c}}(d B / G H z)$

where $\alpha_{\max }$ and $\alpha_{\min }$ show the suppression level of $-40 \mathrm{~dB}$ and $-3 \mathrm{~dB}$. Also, the frequencies corresponding with the suppression levels of $-40 \mathrm{~dB}$ and $3 \mathrm{~dB}$ are $\mathrm{f}_{\mathrm{s}}$ and $\mathrm{f}_{\mathrm{c}}$, respectively. The relative stop-band width (RSB) is given by :

$R S B=\frac{\text { stopband width }}{\text { cut off frequency }}$

The suppression factor (SF) is:

$S F=\frac{\text { suppression level in stopband }}{10}$

The normalized circuit size (NCS) is:

$N C S=\frac{\text { physical size }(\text { length } \times \text { width })}{\lambda_{g}^{2}}$ 
where $\lambda_{\mathrm{g}}$ is the guided wavelength at $1.27 \mathrm{GHz}$ and for 2 dimensional structure the architecture factor (AF) is defined 1. Finally, the FOM is defined as:

$F O M=\frac{R S B \times \xi \times S F}{A F \times N C S}$

Conclusion: A highly selective, compact LPF with an ultrawide stopband is designed through a systematic approach. In this approach, three polygonal resonators are designed, where two resonators are collectively responsible for providing an ultrawide stopband, and the third resonator independently controls the cut-off frequency of the filter with a sharp roll-off. The filter suppresses all spurious bands up to the 19th harmonic, with a very good attenuation of 25 $\mathrm{dB}$, exhibiting an excellent out-of-band characteristic. The fabricated LPF has a high return loss $(20 \mathrm{~dB})$ and negligible insertion loss $(0.25 \mathrm{~dB})$ in the passband. The filter is compact with a very high FOM of $76,331$.

\section{Acknowledgement}

This research has been supported by the Ministry of Education, Youth and Sports of the Czech Republic under the project OP VVV Electrical Engineering Technologies with High Level of Embedded Intelligence CZ.02.1.01/0.0/0.0/18_069/0009855. 


\section{References}

[1] P Rostami, S Roshani, "A miniaturized dual band Wilkinson power divider using capacitor loaded transmission lines," AEU-International Journal of Electronics and Communications, 90, pp. 63-68, 2018.

[2] G Karimi, M Amirian, A Lalbakhsh, M Ranjbar, "A new microstrip coupling system for realization of a differential dual-band bandpass filter," AEU-International Journal of Electronics and Communication, Vol. 99, pp. 186-192, 2019.

[3] A. Lalbakhsh, Muhammad U. Afzal, Karu P. Esselle, Stepanie L. Smith, Basit A. Zeb, "Single-dielectric Wideband Partially Reflecting Surface with Variable Reflection Components for Realization of a Compact High-gain Resonant Cavity Antenna," IEEE Trans. Antennas Propag.,Vo. 67, no. 3, pp.1916-1921, 2019

[4] P. Gooran, A. Lalbakhsh, H. Moradi, and M. Jamshidi "Compact and wideband printed logperiodic dipole array antenna using multi-sigma and multi-Tau techniques," Journal of Electromagnetic Waves and Applications, 2019

[5] A Ahmadi, SV Makki, A Lalbakhsh, S Majidifar, "A novel dual-mode wideband band pass filter," Applied Computational Electromagnetics Society Journal (ACES). Vol. 29, Issue 9, pp.735-742, Sep. 2014

[6] G. Karimi, H. pourasad, A. Lalbakhsh, H. Siahkamari, "Design of a compact ultra-narrow band dual band filter for WiMAX application," AEU-International Journal of Electronics and Communication, Vol. 110, 2019

[7] H. Jia-Sheng, and M. Lancaster, "Microstrip filters for RF/microwave applications," Microwave Magazine, vol. 3, no. 3, pp. 62-65, 2001.

[8] M. U. Afzal, A. Lalbakhsh and K. P. Esselle, "A Low-Profile Beam-Tilted Antenna Array for Receiving Direct-Broadcast Satellite Services," 2018 IEEE Asia-Pacific Conference on Antennas and Propagation (APCAP), Auckland, 2018, pp. 147-148.

[9] A. Lalbakhsh, M. U. Afzal, K.P. Esselle, S. L. Smith, "Low-Cost Non-Uniform Metallic Lattice for Rectifying Aperture Near-Field of Electromagnetic Bandgap Resonator Antennas," IEEE Trans. Antennas Propag. In press, 2020.

[10] J.E. Eng, and S.Y. Frank, Boeing Co, 2019. Low cost millimeter wave receiver and method for operating same. U.S. Patent 10,263,648.

[11] Muhammad U. Afzal, A. Lalbakhsh, Karu P. Esselle, "Electromagnetic-wave beamscanning antenna using near-field rotatable graded-dielectric plates," Journal of Applied Physics, Vol. 124, no. 23 pp. 912-915, 2018.

[12] A. Sheikhi, A. Alipour, and H. Hemesi, "Design of microstrip wide stopband lowpass filter with lumped equivalent circuit," Electronics Letters, vol. 53, no. 21, pp. 1416-1418, 2017. [13] Y. Jiang, B. Wei, Y. Heng, X. Guo, B. Cao, and L. Jiang, "Compact superconducting lowpass filter with wide stopband," Electronics Letters, vol. 53, no. 14, pp. 931-933, 2017.

[14] B. Zhang, S. Li, and J. Huang, "Compact lowpass filter with wide stopband using coupled rhombic stubs,” Electronics Letters, vol. 51, no. 3, pp. 264-266, 2015.

[15] S. Jiang, and J. Xu, "Sharp roll-off planar lowpass filter with ultra-wide stopband up to 40 GHz,” Electronics Letters, vol. 53, no. 11, pp. 734-735, 2017. 
[16] G. Karimi, A. Lalbakhsh, and H. Siahkamari, "Design of sharp roll-off lowpass filter with ultra wide stopband," IEEE Microwave and Wireless Components Letters, vol. 23, no. 6, pp. 303-305, 2013.

[17] J. Xu, Y.-X. Ji, W. Wu, and C. Miao, "Design of miniaturized microstrip LPF and wideband BPF with ultra-wide stopband," IEEE Microwave and wireless components letters, vol. 23, no. 8, pp. 397-399, 2013.

[18] K. Dehghani, G. Karimi, A. Lalbakhsh and S.V. Maki, "Design of lowpass filter using novel stepped impedance resonator," Electronics Letters, vol. 50, no. 1, pp. 37-39, 2014.

[19] C.-J. Chen, C.-H. Sung, and Y.-D. Su, "A multi-stub lowpass filter," IEEE Microwave and Wireless Components Letters, vol. 25, no. 8, pp. 532-534, 2015.

[20] F.-C. Chen, H.-T. Hu, J.-M. Qiu, and Q.-X. Chu, "High-selectivity low-pass filters with ultrawide stopband based on defected ground structures," IEEE Transactions on components, packaging and manufacturing Technology, vol. 5, no. 9, pp. 1313-1319, 2015.

[21] S. Jiang, and J. Xu, "Compact microstrip lowpass filter with ultra-wide stopband based on dual-plane structure," Electronics Letters, vol. 53, no. 9, pp. 607-609, 2017.

[22] S. Roshani, “A compact microstrip low-pass filter with ultra wide stopband using compact microstrip resonant cells," International Journal of Microwave and Wireless Technologies, vol. 9, no. 5, pp. 1023-1027, 2017.

[23] G Karimi, A Lalbakhsh, K Dehghani, H Siahkamari, "Analysis of Novel Approach to Design of Ultra-wide Stopband Microstrip Low-Pass Filter Using Modified U-Shaped Resonator,” ETRI Journal, vol. 37, no. 5, pp. 945-950, 2015.

[24] G Karimi, H Siahkamari, FK Hamedani, A Lalbakhsh, "Design of modified Z-shaped and T-shaped microstrip filter based on transfer function analysis," Wireless Personal Communications, vol. 82, no. 4, pp. 2005-2016, 2015.

[25] H. Sariri, Z. Rahmani, A. Lalbakhsh and S. Majidifar, "Compact LPF Using T-shaped Resonator," Frequenz, vol. 67, no. 1-2, pp. 17-20, 2013.

[26] S. Roshani, K. Dehghani, and S. Roshani, "A Lowpass Filter Design Using Curved and Fountain Shaped Resonators," Frequenz, vol. 73, no. 7-8, pp. 267-272, 2019.

[27] A. Ghaderi, and S. Roshani, "L-Band Microstrip Lowpass Filter with Small Size and Excellent Harmonic Suppression,” Microwave Journal, vol. 61, no. 10, 2018.

[28] Pooia Lalbakhsh, Bahram Zaeri, A. Lalbakhsh, Mehdi N. Fesharaki, "AntNet with Reward-Penalty Reinforcement Learning,"Second International Conference on Computational Intelligence, Communication Systems and Networks (CICSYN2010), Liverpool, UK, pp. 1721, 2010.

[29] Pooia Lalbakhsh, Bahram Zaeri and A. Lalbakhsh, "An Improved Model of Ant Colony Optimization using a Novel Pheromone Update Strategy,” IEICE Trans. Inf. \& Syst. Vol. E96D, No.11, pp. 2309-2318, Nov. 2013.

[30] M. B. Jamshidi, N. Alibeigi, A. Lalbakhsh, “Artificial Neural Networks: A Powerful Tool for Cognitive Science," 2018 IEEE 9th Annual Information Technology, Electronics and Mobile Communication Conference (IEMCON), Vancouver, BC, 2018, pp. 674-679.

[31] Wang, G., Xu, Y., Ge, M., Lu, L. and Jia, Y., 2020. Mode transition and energy dependence of FitzHugh-Nagumo neural model driven by high-low frequency electromagnetic radiation. AEU-International Journal of Electronics and Communications, p. 153209. 
[32] M. B. Jamshidi, A. Lalbakhsh, N. Alibeigi, M. R. Soheyli, B. Oryani and N. Rabbani, "Socialization of Industrial Robots: An Innovative Solution to improve Productivity," 2018 IEEE 9th Annual Information Technology, Electronics and Mobile Communication Conference (IEMCON), Vancouver, BC, 2018, pp. 832-837.

[33] M Hayati, F Shama, S Roshani, A Abdipour,"Linearization design method in class-F power amplifier using artificial neural network," Journal of Computational Electronics 13 (4), 943-949

[34] M. B. Jamshidi, A. Lalbakhsh et al, "Artificial Intelligence and COVID-19: Deep Learning Approaches for Diagnosis and Treatment," IEEE ACCESS, 2020. DOI:10.1109/ACCESS.2020.3001973.

[35] A. Lalbakhsh, Muhammad U. Afzal, Karu P. Esselle, Stephanie Smith, "Design of an artificial magnetic conductor surface using an evolutionary algorithm," in Proc. 19th IEEE international Conference on Electromagnetics in Advanced Applications (ICEAA), Verona, Italy, Sep., 2017

[36] A. Lalbakhsh, Muhammad U. Afzal, B. A. Zeb and Karu P. Esselle, "Design of a dielectric phase-correcting structure for an EBG resonator antenna using particle swarm optimization," in Proc. IEEE. Int Symp. Antennas Propag. (ISAP), Hobart, Australia, Nov., 2015, pp. 408410

[37] Z. Yang, Y. Yao, Y. Jin, M. Li, Z. Geng, Z. Yu, and Z. Li, "Synthesizing and Optimizing of Wide Stopband Low-Pass Filter with Improved Infinite Attenuation Unit Based on Stubs," Frequenz, vol. 72, no. 11-12, pp. 523-531, 2018.

[38] A Karami, GH Roshani, E Nazemi, S Roshani, "Enhancing the performance of a dualenergy gamma ray based three-phase flow meter with the help of grey wolf optimization algorithm," Flow Measurement and Instrumentation 64, 164-172, 2018.

[39] A. Lalbakhsh, M. U. Afzal, and K. P. Esselle, "Multiobjective particle swarm optimization to design a time-delay equalizer metasurface for an electromagnetic band-gap resonator antenna," IEEE Antennas and Wireless Propagation Letters, vol. 16, pp. 912-915, 2017.

[40] M. B. Jamshidi, A. Lalbakhsh, S. Lotfi, H. Siahkamari, B. Mohamadzade, and J. Jalilian, "A Neuro-based Approach to Designing a Wilkinson Power Divider," International Journal of RF and Microwave Computer Aided Engineering, e22091. 2019.

[41] S. Koziel, and A. Bekasiewicz, "On deterministic procedures for low-cost multi-objective design optimization of miniaturized impedance matching transformers," Engineering Computations, vol. 34, no. 2, pp. 403-419, 2017.

[42] A. Lalbakhsh, M. U. Afzal, K. P. Esselle, and S. L. Smith, "Wideband Near-Field Correction of a Fabry-Perot Resonator Antenna," IEEE Transactions on Antennas and Propagation, vol. 67, no. 3, pp. 1975-1980, 2019.

[43] MB Jamshidi, A Lalbakhsh, B Mohamadzade, H Siahkamari, "A Novel Neural-Based Approach for Design of Microstrip Filters," AEU-International Journal of Electronics and Communications, pp. 152847, 2019.

[44] A. Lalbakhsh, M. Afzal, and K. Esselle, "Simulation-driven particle swarm optimization of spatial phase shifters," in Proc. 18th IEEE international Conference on Electromagnetics in Advanced Applications (ICEAA), Australia, Cairns, Australia, Sep., 2016, pp 428-430 
[45] S. Roshani, S. Roshani, and A. Zarinitabar, "A modified Wilkinson power divider with ultra harmonic suppression using open stubs and lowpass filters," Analog Integrated Circuits and Signal Processing, vol. 98, no. 2, pp. 395-399, 2019.

[46] S. Roshani, M. Hayati, S. Setayeshi, S. Roshani, and G. Mohamadpour, "A miniaturized harmonic suppressed power amplifier integrated with lowpass filter for long term evolution application," Analog Integrated Circuits and Signal Processing, vol. 89, no. 1, pp. 197-204, 2016.

[47] Li, Z. and Ho, S.J., Compact Microstrip Lowpass Filter with Ultra-Wide Stopband Characteristic Using Square Ring Loaded Resonators. Progress In Electromagnetics Research, vol. 90, pp.1-5, 2020.

[48] Rekha, T.K., Abdulla, P., Jasmine, P.M. and Anu, A.R., Compact microstrip lowpass filter with high harmonics suppression using defected structures. AEU-International Journal of Electronics and Communications, vol. 115, p.153032, 2020.

[49] Shi, L.F., Fan, Z.Y. and Xin, D.J., Miniaturized low-pass filter based on defected ground structure and compensated microstrip line. Microwave and Optical Technology Letters, vol. 62, no. 3, pp.1093-1097, 2020.

[50] Zhang, H. and Zhao, J., "Compact microstrip lowpass filter with ultra-wide stopband performance using radial stub loaded resonators”, Progress In Electromagnetics Research, vol. 71, pp.199-203, 2018.

[51] A. Lalbakhsh, G. Karimi, F. Sabaghi, "Triple mode spiral wideband bandpass filter using symmetric dual-line coupling," Electronics Letters, Vol. 53, No. 12, pp. 795-797, 2017

[52] Wang, J., He, S., You, F., Shi, W., Peng, J. and Li, C., 2018. Codesign of high-efficiency power amplifier and ring-resonator filter based on a series of continuous modes and even-oddmode analysis. IEEE Transactions on Microwave Theory and Techniques, 66(6), pp.28672878 . 